\title{
para-AMINOBENZOIC ACID STIMULATES SEED GERMINATION PLANT GROWTH, DEVELOPMENT, PHOTOSYNTHESIS AND NITROGEN ASSIMILATION IN THE AMARANTH (Amaranthus L.)
}

\section{L.L. KIRILLOVA', G.N. NAZAROVA ${ }^{2}$, E.P. IVANOVA ${ }^{2}$}

\author{
${ }^{1}$ L.N. Tolstoi State Pedagogical University, 125, prosp. Lenina, Tula, 300026 Russia; \\ ${ }^{2}$ Institute of Basic Biological Problems, Federal Agency of Scientific Organizations, 2, ul. Institutskaya, Pushchino, \\ Moscow Province, 142290 Russia, e-mail cheredova@mail.ru \\ Received August 30, 2015
}

\section{Abstract}

Currently protective, reparative, anti-mutagenic, antioxidant properties of para-aminobenzoic acid (pABA) are described. The huge number of the facts is saved up concerning its efficiency on all elements of yield structure of different plants species and household purposes. However, there is almost no information about the effect of pABA on amaranth plants in the world literature. Vegetable amaranth is a valuable food culture, promising to Central Russia. Therefore, we are especially interested in ways to facilitate its introduction, increase productivity, and nutritional value. To this end, it is possible to use pABA as environmentally friendly biologically active natural compound with a broad spectrum of action. In this work, we first investigated the effect of pABA on seed germination, and growth, development and productivity of vegetable amaranth Amaranthus caudatus L. variety K173 (K173) and A. cruentus L. variety K185 (K185) of grown plants as well as on light-dependent processes of photosynthesis and nitrogen assimilation in the leaves. To assess the characteristics and level of pABA activity the experimental results concerning influence of a synthetic citokinin 6benzilaminopurin (6-BAP) on the same parameters are given. A dependence of amaranth seed germination on pABK $10^{-9} \mathrm{M}$ to $10^{-4} \mathrm{M}$ concentration used for treatment was found. The seed germination in both varieties was $23 \pm 5 \%$ higher at $10^{-6} \mathrm{M}$ pABK, whereas $10^{-4} \mathrm{M}$ pABK decreased it by $22 \pm 4 \%$, and other concentrations had no significant effect. In K173 the 15-day seedlings exceeded the control by $10 \pm 5 \%$ in height, by $76 \pm 6 \%$ in weight, and by $133 \pm 17 \%$ in root length at the latent growth stage. Parameters of K185 plants were slightly higher. The acceleration of plant development may contribute to survival and adaptation. Stimulating effect of pABA on K173 and K185 plant growth in height is maintained for the life of plants, except initiation of generative organs (days 6080 ). A significant increase (30-85\%) in plant weight compared to control was identified at all stages of ontogenesis. Productivity of leaf biomass per plant in both varieties on day 115 was on average $50 \pm 11 \%$ more than in the control. In the leaves of 45-day plants of K173 grown from treated seed, the activity of nitrate reductase increased by $37 \pm 4 \%$ and the total protein level was $10 \pm 3 \%$ higher when compared to control, thus improving nutritional value of the culture. The rate of photophosphorylation in chloroplasts was shown to be $27 \pm 6 \%$ higher, and the rate of electron transport was $32 \pm 6 \%$ higher in comparison with the control that led to an increase in leaf net photosynthesis by $22 \pm 7 \%$. These were no different from 6-BAP effects. The pABA influence on the seed germination and plant biometric parameters in K173 and K185 was comparable to the action of 6-BAP. pABK influenced nitrate reductase activity, protein level, chlorophyll content, and photophosphorylation rate in leaves of K173 plants much weaker, than 6-BAP, and differed from it. The pABA properties as a plant hormone are discussed, and the use is recommended for the vegetable amaranth cultivation.

Keywords: amaranth, para-aminobenzoic acid, plant hormones, seed germination, plants growth and development, latent growth, adaptation, productivity, chloroplasts, photophosphorylation, electron transport, protein content, nitrogen assimilation, nitrate reductase

The first reports on the stimulatory action of p-aminobenzoic acid (pABA) on plants were made many decades ago [1]. Up to date, its reparative [2], protective [3], anti-mutagenic [4], antioxidant [5], and phytohormone [6] properties have been established. Such a variety of effects is explained by the fact that pABA is a folate component [7] which is an essential cofactor of onecarbon unit transfer reactions [8]. Therefore, a residue of pABA is involved in many key processes, such as biosynthesis of purines, pyrimidines, pantothenate, 
synthesis of S-adenosyl-1-methionine (SAM), formyl-methionine-tRNA, deoxyribonucleotides, as well as in transformation of amino acids [9]. The important role of pABA as a folate component in the regulation of the activity of DNA polymerase, DNAase and RNAase [10, 11], in transcription [12], in promoting phosphorylation, oxidative phosphorylation, photorespiration [8], etc. has been demonstrated. However, there are some new facts that do not fall into this pattern. This is true, for example, for the antioxidant [13] and some of the protective properties [14] identified in the pABA itself. It has been found recently a direct involvement of pABA in the regulation of activity of an oxidative stressrelated enzyme, such as peroxidase [15]. The ability of pABA to induce the acquired systemic disease-resistance in plants was demonstrated [16]. It could well be the case that hormone-like properties of pABA are not limited just to its contribution to the folate regulation of synthesis of purines [8], while may be related to its molecule features [17].

A great body of factual evidence has been accumulated about the beneficial effects of pABA on all structural components of the yield for the plants of different species and economic designation, such as cereals (barley, oats, corn, wheat), legumes (peas, lupine), vegetables (cucumbers, tomatoes), cotton, grapes, etc. $[1,2,5,6,18-20]$. In addition, the pre-planting treatment of seeds was mainly applied. Despite the abundance of such information, we have found only a single report on the use of pABA in amaranth [21], where it was used «for phenotypic correction of morphological characters». The weight of seeds on the plant was increased following the spraying of the amaranth inflorescences. The most effective concentration of pABA was $0.02 \%\left(1.5 \times 10^{-3} \mathrm{M}\right)$. We suggested that pABA may also have regulatory effects on amaranth plants if seed treatment would be used.

Our interest in vegetable amaranth stems from the fact that this important food crop with its high content of a well-balanced protein is very promising for the Central Russia region [22]. To facilitate its introduction, increase the productivity and nutritional value, it seems possible to use pABA, being a biologically active compound with a broad spectrum of action and an environmentally friendly substance due to its natural origin. The results of such use of pABA could replenish gap in evidence on its effects on photosynthetic and assimilatory processes.

Our aim was to investigate the action of p-aminobenzoic acid (pABA) on seeds of vegetable amaranth belonging to two cultivars and varieties and plants grown from them in order to evaluate the possibility of using this substance for the amaranth cultivation in Central Russia. The objectives were to determine the growth parameters in plants of different varieties throughout their ontogeny, as well as to assess the activity of nitrogen assimilation and photosynthetic processes based on the parameters of the light-dependent stage of photosynthesis in one of the varieties. The experiments, aimed to assess the magnitude and nature of the pABA activity, involved a comparison with the effects of a synthetic cytokinin 6-benzylaminopurine (6-BAP).

Techniques. In this paper, we used the seeds of vegetable amaranth, such as Amaranthus caudatus L., the K173 variety (K173) and A. cruentus L., the K185 variety (K185), obtained from the All-Russian Research Institute of Vegetable Breeding and Seed Production (Moscow Province, Russia).

To determine the effect of pABA and 6-BAP (crystalline preparative forms, Sigma-Aldrich Corp., USA) on the germination, seeds of amaranth were soaked in aqueous solutions of the preparations (from $10^{-9}$ to $10^{-4} \mathrm{M}$ ) for $24 \mathrm{~h}$. Seeds were then dried in a weak stream of air at room temperature. Seeds soaked in the distilled water were used as a control. The germination was determined by a percentage of sprouted seeds from a total number of seeds after their incubation on moist filter paper in Petri dishes for 72 hours at $24{ }^{\circ} \mathrm{C}$. 
To examine the growth and biochemical parameters, the plants were derived from seeds treated with $1 \mu \mathrm{M}$ solutions of pABA or 6-BAP (test) or with distilled water (control) as described above. The germinated seeds were planted in pots filled with sand (10 calibrated seedlings per pot, with 3 pots per each variant of the experiment), and plants were grown at $24{ }^{\circ} \mathrm{C}$, with a 14 -hour photoperiod and at the illumination of $150 \mathrm{~W} \cdot \mathrm{m}^{-2}$; the Knopp growth medium was used for watering. Biometric parameters were taken every 15 days up to the harvest date (Day 115), and the productivity was assessed by biomass gain. The chlorophyll content was determined in the leaves of 45-day-old plants [23]; photochemical activity of chloroplasts, isolated [24] from these leaves, was evaluated based on the electron transport rates [25] and phosphorylation [26]. The activity of nitrate reductase (NR), the amounts of nitrite [27], the content of nitrogen [28] and total protein levels [29] were measured in the leaves of plants aged from day 15 to day 45 . Photosynthetic productivity $\left(\mathrm{PP}, \mathrm{g} \cdot \mathrm{m}^{-2} \cdot \mathrm{day}^{-1}\right)$ was calculated over the interval between day 45 to day 55 by Nichiporovich method [30].

The article shows the results of one representative experiment out of five. Biometric parameters were determined in 30 plants. Biochemical analyzes were arranged in 3 repetitions. The tables and diagrams provide arithmetic means with a standard error. The significance of differences was assessed by the Student's $t$ test at $\mathrm{P}=0.95$.

Results. The germination of the amaranth seeds depended on the concentration of the pABA and 6-BAP solutions used for treatment (Fig. 1). In untreated seeds, it was $70 \%$. The exposure to pABA resulted in its significant increase by $23 \pm 5 \%$ at a concentration of $10^{-6} \mathrm{M}$ or decrease by $22 \pm 6 \%$ at $10^{-4} \mathrm{M}$. The effect of 6-BAP was similar. As $10^{-6} \mathrm{M}(1 \mu \mathrm{M})$ appeared to be the optimal concentration of the solutions for germination, it was then used in the experiments. Data on seed germination for K185 and K173 almost did not differ.

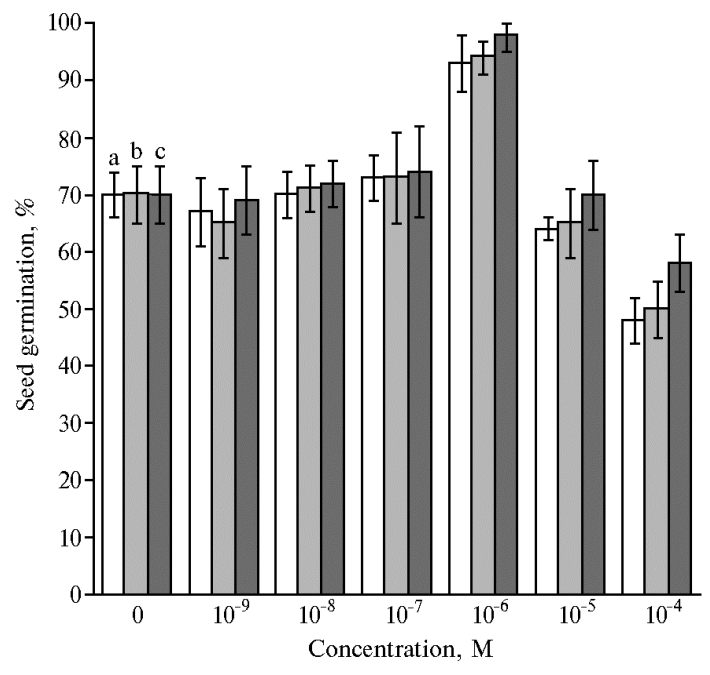

Fig. 1. Germination of seeds in vegetable amaranth Amaranthus caudatus L. variety K173 (a), and $A$. cruentus $\mathrm{L}$. variety $\mathrm{K} 185$ (b), treated with p-aminobenzoic acid, and in $A$. caudatus $\mathrm{L}$. variety K173, treated with 6-benzylaminopurine (c) $(X \pm x$, lab experiment).

We found that after seed pre-treatment with $1 \mu \mathrm{M}$ pABA the 15-day-old K173 and K185 seedlings were superior to control - in height by $10 \pm 5 \%$ (for 6-BAP by $22 \pm 4 \%)$ and in weight by $76 \pm 6 \%$ (for 6-BAP by $129 \pm 8 \%$ ) (Fig. 2). Usually, during this period of development, the above-ground parts stunt the growth (so-called latent phase). The presented data show that the seedlings have passed the mentioned phase under the influence of both stimulants, however, the effect of 6-BAP was stronger. It should be noted that a significant acceleration of root growth was observed concurrently. The length of the main root in control plants averaged to $1.2 \pm 0.1 \mathrm{~cm}$, while after exposure to pABA it was $2.8 \pm 0.3 \mathrm{~cm}$, and after 6 -BAP $3.3 \pm 0.3 \mathrm{~cm}$, or $233 \pm 10 \%$ and $275 \pm 9 \%$ respectively, as compared to control. The effect of 6-BAP on all parameters in the 15-day-old seedlings was much stronger than that of pABA. The effects from the stimulants on the parameters of the K185 seedlings were similar to those in the 


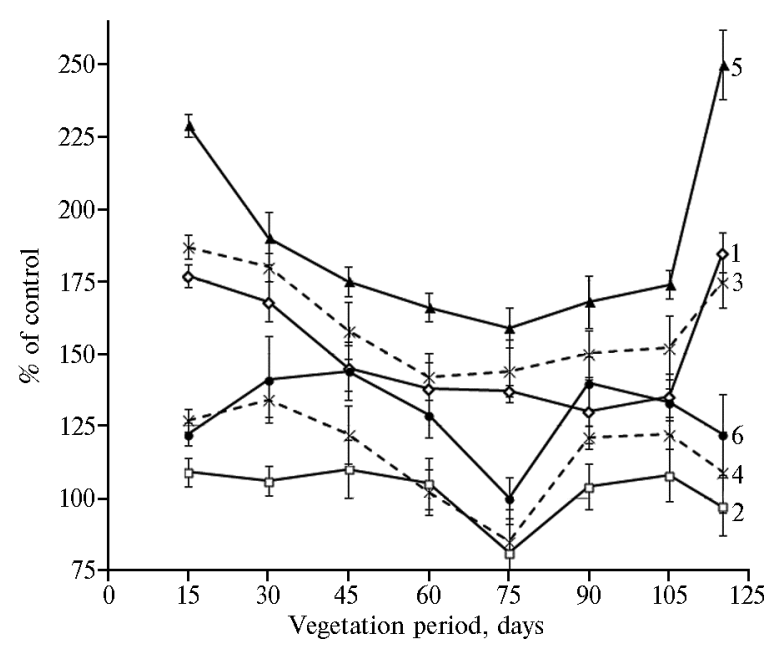

Fig. 2. Plant growth in two varieties of vegetable amaranth after seed pre-treatment with p-aminobenzoic acid (pABA) and in one variety after exposure to 6benzylaminopurine (6-BAP): 1, $2-\mathrm{Am}$ aranthus caudatus L., K173; 3, 4, 5, 6 A. cruentus L., K185; 1, 3, 5 - the weight, 2, 4, 6 - the height; 1, 2, 3, 4 - pABA, 5, 6 - 6-BAP $(1 \mu \mathrm{M}$ solutions) ( $X \pm x$, lab experiment).

The stimulating effect of pABA on height was maintained throughout the life of plants, except for the period of the initiation of generative organs (60-80 days) (Fig. 2). A significant weight increase in the whole plants was observed

at all stages of ontogenesis as compared to the control. The maximum effect was observed at harvesting (day 115), when the weight of the above-ground parts of the plants, grown from seeds treated with pABA, exceeded that in the control by $85 \pm 10 \%$. The nature of the pABA and 6-BAP effects on the plant height and weight in ontogeny coincided (see Fig. 2), but the degree of influence of the latter was higher. Trends in growth parameters for the second variety, K185, when using growth regulators, fully reproduced their pattern for the K173 variety, however, absolute values were slightly higher.

The main productivity indicator for the vegetable forms of amaranth is the output of the leaf biomass on the plants. On day 115, its values for the K173 variety under the influence of pABA averaged to $130 \pm 10 \mathrm{~g}$ in control, and to $195 \pm 14 \mathrm{~g}$ in the test that is $50 \pm 11 \%$ higher as compared to control. This parameter for K185 exceeded that in control by $68 \pm 9 \%(160 \pm 14 \mathrm{~g}$ against $95 \pm 6 \mathrm{~g}$ in control). The weight per $1 \mathrm{~m}^{2}$ of leaves for the $\mathrm{K} 173$ plants, when seed pre-

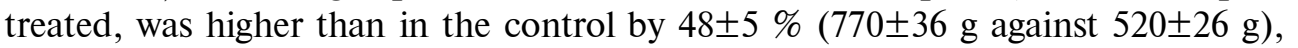
and for the K185 plants by $40 \pm 8 \%$. 6-BAP increased the output of leaf biomass by $62 \pm 9 \%$, and the weight per $1 \mathrm{~m}^{2}$ of leaves by $61 \pm 8 \%$. These data suggest that there was little or no significant difference between the influence of pABA and 6-benzyladenine on the leaf mass productivity in both varieties.

As the productivity of plants is largely determined by the activity of the photosynthetic apparatus, we have studied the photochemical activity of isolated chloroplasts. In the chloroplasts from leaves of the K173 45-day-old plants, we revealed an increase, compared to the control, in both electron transport rates and ATP synthesis rates if the pre-planting seed treatment with pABA and 6BAP was used (Table 1). Meanwhile, the effect of 6-BAP on the ATP production rate was significantly stronger than that of pABA, with almost equal effects of both on the electron transport. The difference in the effect between two bioactive agents consisted in the fact that exposure to pABA resulted in the unchanged content of chlorophyll in the leaves, while under the influence of 6BAP it greatly increased. Despite that, the values of PP in the leaves from growth day 45 to day 55 in the tests with pABA and 6-BAP did not differ significantly: PP values decreased with pABA by $22 \pm 7 \%$ vs. control (from $2.3 \pm 0.15$ to $2.8 \pm 0.19 \mathrm{~g} \cdot \mathrm{m}^{-2} \cdot \mathrm{day}^{-1}$ ), and with 6 -BAP by $30 \pm 5 \%$ (from $2.3 \pm 0.15$ to $\left.3.0 \pm 0.15 \mathrm{~g} \cdot \mathrm{m}^{-2} \cdot \mathrm{day}^{-1}\right)$. 
1. Photosynthetic activity in isolated chloroplasts from leaves of 45-day-old amaranth plants (Amaranthus caudatus L., K173 variety) after seed pre-treatment with $\mathbf{p A B A}$ and 6-BAP $(X \pm x$, lab experiment)

\begin{tabular}{l|cc|cc|c|c}
\hline \multirow{3}{*}{ Option } & \multicolumn{2}{|c|}{ Chlorophyll content } & \multicolumn{4}{|c}{ Rates of } \\
\cline { 3 - 7 } & \multicolumn{2}{|c|}{} & \multicolumn{2}{c}{ electron transport } & \multicolumn{2}{c}{ photophosphorylation } \\
\cline { 2 - 7 } & $\mathrm{mg} / \mathrm{g}$ dry weight & vs. control, $\%$ & $\mu \mathrm{M} \mathrm{K}_{3}\left[\mathrm{Fe}\left(\mathrm{CN}_{6}\right)\right]$ & vs. control, \% & $\mu \mathrm{M}$ ATP & vs. control, \% \\
\hline Control & $9.9 \pm 0.2$ & 100 & $110.4 \pm 8.0$ & 100 & $112.0 \pm 2.3$ & 100 \\
pABA & $9.9 \pm 0.6$ & $100 \pm 6$ & $145.9 \pm 7.0$ & $132 \pm 6$ & $142.0 \pm 2.0$ & $127 \pm 6$ \\
6-BAP & $14.4 \pm 2.2$ & $146 \pm 15$ & $148.5 \pm 15.0$ & $135 \pm 14$ & $209.0 \pm 15.0$ & $186 \pm 13$
\end{tabular}

N o t e. pABA - p-aminobenzoic acid, 6-BAP - 6-benzylaminopurine. The rate is calculated per $1 \mathrm{mg}$ of chlorophyll per 1 hour. The concentration of pABA and 6-BAP solutions is $1 \mu \mathrm{M}$.

Applying both pABA and 6-BAP $(1 \mu \mathrm{M})$ led to an increase in the NR activity, compared to the control, during the first 45 days of vegetation, providing the enhanced synthesis of nitrogen-based compounds during the active growth and their consumption for plastic processes (Table 2). However, the nature of the effects induced by these two stimulants was different. In the pABA group the NR activity consistently exceeded that in the control (by an average of $34 \%$ ), whereas in the 6-BAP group it increased gradually along with the plant growth. At that, the 6-BAP effect was significantly stronger than that of pABA.

Treatment with both pABA and 6-BAP caused elevated levels of total protein in leaves of the K173 amaranth plants from day 15 to day 45 . Neverthelwss, during the growth a downward trend in the total protein levels was observed upon exposure to both bioactive agents, although with 6-BAP the total protein values remained significantly higher at day 45 . Under the influence of pABA (unlike 6-BAP), nitrite accumulation by leaves was not observed. Nitrate reductase activity, the percentage of $\mathrm{N}$ and total protein levels in plants do not always directly correlate [31]. However, we have established significant stimulating effects of $\mathrm{pABA}$ on the nitrogen assimilation and transformation in amaranth plants (see Table 2).

2. Changes in nitrogen metabolism (vs. control, \%) in the leaves of amaranth plants (Amaranthus caudatus L., K173 variety) after seed pre-treatment with pABA and 6-BAP $(X \pm x$, lab experiment)

\begin{tabular}{l|c|c|c|c|c}
\hline \multirow{2}{*}{ Option } & Plant's age, days & Nitrite & Nitrate reductase activity & \multicolumn{2}{|c}{ Total } \\
\cline { 3 - 5 } & & & nitrogen & protein \\
\hline pABA & 15 & $143 \pm 5$ & $101 \pm 2$ & $130 \pm 2$ & $104.0 \pm 0.5$ \\
& 30 & $108 \pm 3$ & $134 \pm 2$ & $102.0 \pm 1.1$ & $128 \pm 9$ \\
& 45 & $124 \pm 4$ & $137 \pm 4$ & $102.0 \pm 0.7$ & $110 \pm 6$ \\
6-BAP & 15 & $109 \pm 2$ & $147 \pm 9$ & $108.0 \pm 0.4$ & $142 \pm 9$ \\
& 30 & $122 \pm 5$ & $167 \pm 12$ & $105.0 \pm 0.5$ & $137 \pm 9$ \\
& 45 & $65 \pm 18$ & $106.0 \pm 1.2$ & $138 \pm 14$
\end{tabular}

N o t e. pABA - p-aminobenzoic acid, 6-BAP - 6-benzylaminopurine. The concentration of pABA and 6-BAP solutions is $1 \mu \mathrm{M}$.

The identified effect of pre-planting seed treatment with pABA on the commercially significant characteristics of amaranth was associated with its impact on the fundamental underlying physiological and biochemical processes. For the first time we demonstrated the promotion of the light-dependent reactions of photosynthesis and nitrogen assimilation rates in the K173 variety by the use of pABA. It should be noted that the nature and magnitude of some studied effects of pABA and 6-BAP varied, therefore, pABA does not act as a cytokinin. The high content of $\mathrm{pABA}$ as a folate precursor is likely to stimulate their synthesis and accumulation at the early stages of plant development from a seed, accelerating the physiological and biochemical processes throughout the ontogeny and resulting in the observed effects.

However, another mechanism may also exist. Particularly, there are some scarce evidence about the cytokine $[1,6]$ and auxin $[17,32]$ effects of pABA. Alt- 
hough this area, in fact, has not been studied, there is no reason to deny that pABA does possess some properties typical for phytohormones, i.e. the ability to express a nuclear response through a system of messengers, as it is described, for example, for cytokinins [33]. There may also exist the interaction with phytohormone receptors [18]. The observed effects of pABA indicate in favor of such an assumption, considering the common features of plant hormones according to the International Plant Growth Substance Association (IPGSA). According to IPGSA, phytohormones are natural organic compounds that impact the physiological processes (growth, differentiation, development of the plant, etc.) at much lower concentrations than nutrients or vitamins [34]. The identified effects can not be determined as typical for any known class of plant hormones, and, for now, there is a lack of available factual data to claim a new class. We agree with the suggestion about hormonal activity of some small molecules [35]. Moreover, we have described the cytokinin-like properties of 4-hydroxyethylphenol alcohol, and made an assumption about its hormonal nature [36]. It was based on a precedent revealed for o-hydroxybenzic (salicylic) acid. Currently, this small molecule along with several of its derivatives are recognized as a special class of plant hormones. It may well be possible that with the buildup of data on small molecules some common characteristics may manifest themselves so that to allow combining them into a new group of compounds with specific phytohormonal properties.

Therefore, pre-planting treatment of seeds of vegetable amaranth with $1 \mu \mathrm{M}$ aqueous solution of p-aminobenzoic acid (pABA) improves germination and enhances biometric, physiological and biochemical parameters of plants, i.e. accelerates the development of seedlings in the latent phase of growth, increases growth, improves productivity and nutritional value. The effects of pABA and a cytokinin 6-benzylaminopurine are not identical. pABA can be recommended for the use in cultivation of vegetable amaranth in the Nonchernozem belt of Russia

\section{REFEREN CES}

1. M a cht D.I. Influence of sulfonamides and para-aminobenzoic acid on the growth of Lupinus albus. Exp. Biol. Med., 1945, 60: 217-220 (doi: 10.3181/00379727-60-15140).

2. R a p o p o r t I.A., Vas i l' e va S.V., D a v n i c h e n k o L.S. DAN, 1979, 247(1): 231234 (in Russ.).

3. Tashenova A.A., Kulumbetova S.K., Sinel'shchikova T.A., Akhmatulli na N.B., Zasukhina G.D., Rapoport I.A. Treatment of cells with para-aminobenzoic acid reduces the number of DNA breaks induced by chemical mutagens. Dokl. Akad. Nauk SSSR, 1990, 311(4): 977-979.

4. Gi c hner T., B a d a e v S.A., Pospísil F., Vele míns ký J. Effects of humic acids, para-aminobenzoic acid and ascorbic acid on the $\mathrm{N}$-nitrosation of the carbamate insecticide propoxur and on the mutagenicity of nitrosopropoxur. Mutat. Res., 1990, 229(1): 37-41 (doi: 10.1016/0027-5107(90)90006-P).

5. Eiges N.S., Volchenko G.A., Volchenko S.G., Vaisfel'd L.I., Kozlov V.S., D o net s N.V. Avtokhtonni ta introdukovani roslini, 2012, 8: 71-78 (in Russ.).

6. Cronenberg L., Abe 11 e T., P a che co H. New synthetic substances with phytohormonal properties. Bull. Soc. Chim. Biol., 1964, 46: 703-715.

7. B asset G.J., Quinlivan E.P., Ravanel S., Rebeille F., Nichols B.P., Shi nozaki K., Seki M., Adams-Philli ps L.C., Giovannoni J.J., Gregory J.F. III, H a n s o n A.D. Folate synthesis in plants: the p-aminobenzoate branch is initiated by a bifunctional PabA-PabB protein that is targeted to plastids. PNAS USA, 2004, 101: 1496-1501 (doi: 10.1073/pnas.0308331100).

8. Rebeille F., Ravanel S., Jabrin S., Douce R., Storozhenko S., van der $\mathrm{Str}$ a ete $\mathrm{n}$ D. Folates in plants: biosynthesis, distribution, and enhancement. Physiologia Rlantarum, 2006, 126: 330-342 (doi: 10.1111/j.1399-3054.2006.00587.x).

9. Hans o n A.D., R oje S. One-carbon metabolism in higher plants. Annu. Rev. Plant Biol., 2001, 52: 119-137 (doi: 10.1146/annurev.arplant.52.1.119).

10. Kozhevnikova N.A., Ra p op o rt I.A. Ability of para-aminobenzoic acid to restore the activity of alkaline ribonuclease. Izv. Akad. Nauk SSSR Biol., 1987, 5: 787-791. 
11. Kozhevnikova N.A., Rapoport I.A., Ivanitskaya E.A., Pudrina I.D. DAN, 1983, 273(2): 476-479 (in Russ.).

12. Traus c h J.J., B a t e y R.T. A disconnect between high-affinity binding and efficient regulation by antifolates and purines in the tetrahydrofolate riboswitch. Chem. Biol., 2014, 21(2): 205216 (doi: 10.1016/j.chembiol.2013.11.012).

13. Sochor J., Zitka O., Skutkova H., Pavlik D., Babula P., Krska B., Horna A., Ad a m V., Provaznik I., Kizek R. Content of phenolic compounds and antioxidant capacity in fruits of apricot genotypes. Molecules, 2010, 15(9): 6285-6305 (doi: 10.3390/molecules15096285).

14. Mostovshchikova S.M., B e loz e rova A.A. Uspekhi sovremennogo estestvoznaniya, 2013, 8: 20-21 (in Russ.).

15. Pozdnyakova N., Makarov O., Chernyshova M., Turkovskaya O., Jar o s z -Wilk o la z k a A. Versatile peroxidase of Bjerkandera fumosa: substrate and inhibitor specificity. Enzyme Microb. Technol., 2013, 52(1): 44-53 (doi: 10.1016/j.enzmictec.2012.10.005).

16. Song G.C., Choi H.K., R y u C.M. The folate precursor para-aminobenzoic acid elicits induced resistance against Cucumber mosaic virus and Xanthomonas axonopodis. Ann. Bot., 2013, 111(5): 925-934 (doi: 10.1093/aob/mct049).

17. Crisan M.E., B ourosh P., Maffei M.E., Forni A., Pieraccini S., Sironi M. $\mathrm{Chu} \mathrm{m}$ a k ov Y.M. Synthesis, crystal structure and biological activity of 2-hydroxyethylammonium salt of p-aminobenzoic acid. PLoS One, 2014, 9(7) (doi: 10.1371/journal.pone.0101892).

18. S olo ne nk о Үг.A., A le k s e i c huk G.N. Vestsi Natsyyanal'nai akademii navuk Belarusi, 2005, 5(2): 63-66 (in Russ.).

19. Eiges N.S. V sbornike: Khimicheskie mutageny $i$ para-aminobenzoinaya kislota $v$ povyshenii urozhainosti sel'skokhozyaistvennykh rastenii [In: Chemical mutagens and para-aminobenzoic acid in increasing crop productivity]. Moscow, 1989 (in Russ.).

20. S h e r e r V.A., G a d i e v R.Sh. Primenenie regulyatorov rosta v vinogradarstve $i$ pitomnikovodstve [Growth regulators for viticulture and nursery]. Kiev, 1991.

21. B o m e N.A., G ov o r u k hi n a A.A. Vestnik Tyumenskogo gosudarstvennogo universiteta, 1998, 2: 176-182 (in Russ.).

22. K o n o n k ov P.F., P i v o v a rov V.F., G i n s V.K., G i n s M.S. Introduktsiya $i$ selektsiya ovoshchnykh kul'tur dlya sozdaniya novogo pokoleniya produktov funktsional'nogo deistviya [Introduction and breeding vegetables to create a new generation of functional foods]. Moscow, 2008 (in Russ.).

23. Wintermans J.F.G.M., D e Mots A. Spectrophotometric characteristics of chlorophyll a and $\mathrm{b}$ and their pheophytins in ethanol. Biochem. Biophys. Acta, 1965, 109(2): 448-453.

24. We st K.R., W is k i c h J.T. Photosynthetic control by isolated pea chloroplasts. Biochem. J., 1968, 109(4): 527-532 (doi: 10.1042/bj1090527).

25. I z a v a S., G o o d N.E. Hill reaction rates and chloroplasts fragment size. Biochem. Biophys. Acta, 1965, 109: 373-381.

26. B jorkmann O.M., B o ardman N.K., Anderson J.M. Chloroplast components and Structure. Carnegie Inst. Year Book, 1972, 71: 115-135.

27. H a ge ma n R.H., Re ed A.J. Nitrate reductase from higher plants. Methods in Enzymology, 1980, 69: 270-280 (doi: 10.1016/S0076-6879(80)69026-0).

28. S m a rt M.M., R a d a R.G., D o n ne $\mathrm{rm}$ e y e $r$ G.N. Determination of total nitrogen in sediments using persulfate digestion an evaluation and comparison with Kjeldahl procedure. Water Res., 1983, 17(9): 1207-1211 (doi: 10.1016/0043-1354(83)90063-5).

29. B redford A. Rapid and sensitive gram quantities of protein utilizing the principle of protein-dye binding. Analytical Biochemistry, 1976, 72: 248-254.

30. $\mathrm{N}$ i c h i p o r o v i h A.A. Fotosinteticheskaya deyatel'nost' rastenii kak osnova ikh produktivnosti $v$ biosfere $i$ zemledelii [Photosynthetic activity of plants as the basis of productivity in the biosphere and agriculture]. Moscow, 1988 (in Russ.).

31. Che es e man J.M., T a n k o u S.K. Nitrate reductase and growth of Arabidopsis thaliana in solution culture. Plant and Soil, 2005, 266: 143-154 (doi: 10.1007/s11104-005-0947-1).

32. $\mathrm{C}$ ris a $\mathrm{n}$ S.F., G a r a $\mathrm{A}$ A.S. Influence of p-aminobenzoic acid on the activity of indoleacetic acid oxidase. Experientia, 1968, 15(24-10): 1009-1010.

33. H u t c h i s o n C.E., K i e b e r J.J. Signaling via histidine-containing phosphotransfer proteins in Arabidopsis. Plant Signal Behav., 2007, 2(4): 287-289.

34. Plant hormones: biosynthesis, signal transduction, action! P.J. Davies (ed.). London, 2010.

35. B e kt a s Y., Eulge m T. Synthetic plant defense elicitors. Front. Plant Sci., 2015, 5: 1-17 (doi: 10.3389/fpls.2014.00804).

36. Iva nova E.P., K i ri 11 o v a L.L., S m olyg i n a L.D., S e rd y u k O.P. Sel'skokhozyaistvennaya biologiya [Agricultural Biology], 2011, 5: 118-122. Available http://www.agrobiology.ru/52011ivanovae.html. No date (in Russ.). 